\title{
Cooperative effect of heparan sulfate and laminin mimetic peptide nanofibers on the promotion of neurite outgrowth
}

\author{
Busra Mammadov, Rashad Mammadov, Mustafa O. Guler, Ayse B. Tekinay* \\ Institute of Materials Science and Nanotechnology, National Nanotechnology Research Center (UNAM), Bilkent University, Ankara 06800, Turkey
}

\section{A R T I C L E I N F O}

\section{Article history:}

Received 28 September 2011

Received in revised form 1 February 2012

Accepted 6 February 2012

Available online 13 February 2012

\section{Keywords:}

Neural differentiation

PC-12 cells

Peptide amphiphiles

Laminin mimetic

Heparan sulfate mimetic

\begin{abstract}
A B S T R A C T
Extracellular matrix contains an abundant variety of signals that are received by cell surface receptors contributing to cell fate, via regulation of cellular activities such as proliferation, migration and differentiation. Cues from extracellular matrix can be used for the development of materials to direct cells into their desired fate. Neural extracellular matrix (ECM) is rich in axonal growth inducer proteins, and by mimicking these permissive elements in the cellular environment, neural differentiation as well as neurite outgrowth can be induced. In this paper, we used a synthetic peptide nanofiber system that can mimic not only the activity of laminin, an axonal growth-promoting constituent of the neural ECM, but also the activity of heparan sulfate proteoglycans in order to induce neuritogenesis. Heparan sulfate mimetic groups that were utilized in our system have an affinity to growth factors and induce the neuroregenerative effect of laminin mimetic peptide nanofibers. The self-assembled peptide nanofibers with heparan sulfate mimetic and laminin-derived epitopes significantly promoted neurite outgrowth by PC12 cells. In addition, these scaffolds were even effective in the presence of chondroitin sulfate proteoglycans (CSPGs), which are the major inhibitory components of the central nervous system. In the presence of these nanofibers, cells could overcome CSPG inhibitory effect and extend neurites on peptide nanofiber scaffolds.
\end{abstract}

(c) 2012 Acta Materialia Inc. Published by Elsevier Ltd. All rights reserved.

\section{Introduction}

Traumatic nerve injuries, including peripheral nerve injuries and spinal cord injuries, lead to the disability of more than 17,000 people in the USA every year [1,2]. Although some of the peripheral injuries can partially recover spontaneously, some injuries do not recover even after painful surgeries. Poor regenerative capacity of neural tissue results in loss of motor abilities in patients, leading to serious economic loss due to patient care expenses. For a successful therapeutic approach, the natural environment of cells that contains inducers of neural differentiation and neurite outgrowth should be considered. Neural extracellular matrix (ECM) is composed of a variety of proteins and proteoglycans that are either permissive - some being instructive in fact - or restrictive for neurite outgrowth. Balance between the abundance of permissive and restrictive components is essential for the central nervous system (CNS) to function accurately in terms of neurite outgrowth and synaptic activity. This balance becomes chaotic after CNS injury by upregulation of chondroitin sulfate proteoglycans (CSPGs), the main inhibitory ECM component, in glial scar, which leads to poor regeneration [3-5]. Hence, any

\footnotetext{
* Corresponding author. Tel.: +90 312290 3572; fax: +90 3122664365 .

E-mail address: atekinay@bilkent.edu.tr (A.B. Tekinay).
}

attempt aiming at neural regeneration after injury should consider this unbalanced environment in which neurons that still survive reside in. In order to regain functionality of these remaining neurons, a properly designed extracellular niche with neurite outgrowth promoting clues should be provided. This designed niche should also aid neurons to overcome the pathologically abundant inhibitory components and make new synaptic connections to tolerate the loss of neurons caused by injury [6].

Laminin is the major ECM element in CNS and peripheral nervous system (PNS) basement membranes and it is essential for axonal growth as well as for myelination of axons by Schwann cells [7]. Laminin works as an effective neurite-outgrowth-promoting molecule in vitro as well [8-12]. Besides interacting with neurons through integrin receptors, laminin also interacts with other ECM components such as heparan sulfate proteoglycans (HSPG) [1317]. Laminin-HSPG complex formation upon their noncovalent interaction was observed to enhance neurite promoting activity in vitro $[18,19]$. Heparan sulfate (HS) and heparin are highly sulfated glycosaminoglycans (GAGs) that are known by their high affinity to growth factors. Growth factor-GAG interactions stabilize growth factors, increase their local concentration in the ECM and provide proper conformation for receptor interaction [20]. Hence, laminin-HSPG and laminin-heparin complexes have potential of being a dual inducer of neurite outgrowth by inducing cells 
through integrin receptors and HSPG stabilized growth factors simultaneously. Although affinity of HSPG and heparin to neurotrophins such as nerve growth factor (NGF) is moderate, their affinity to heparin enables their slow release in the abundance of heparin [21]. Binding of NGF to heparin also enhances bioactivity of NGF [21]. In addition, heparin stabilizes laminin networks and enhances their functions, leading to improved neuritogenesis by heparin-laminin complexes [22,23].

Bioactive epitopes from neurite inducer proteins have previously been used for decoration of scaffold surfaces instead of their full length versions in order to obtain biofunctional materials. These synthetic materials can mimic the natural environment of neural cells and enhance neurite outgrowth as well as neural differentiation of stem cells. Peptide amphiphile (PA) nanofibers are among the most versatile scaffolds because of their ease of modification by using simple chemistry. These nanofiber scaffolds can be designed according to the needs of a variety of tissues just by changing their biofunctional peptide sequence. The PA molecules form nanofibers by internalization of hydrophobic alkyl tails in aqueous environment where epitope-forming amino acids are presented on the surface of the nanofibers. Laminin epitope (IKVAV)carrying peptide amphiphiles were shown to efficiently induce neural differentiation of stem cells [24]. These laminin-derived PAs were also tested in vivo and found to promote axonal growth, serotonergic fiber plasticity and inhibit glial scar formation after spinal cord injury $[25,26]$.

In this study, heparan-sulfate-mimicking PA (HSM-PA) molecules were used for the first time for promoting neurite outgrowth. Heparan sulfate interacts with a variety of ECM molecules as well as growth factors in the cells' microenvironment. Herein, a selfassembling peptide scaffold was formed by heparan-sulfate-mimicking peptide nanofibers along with laminin-derived peptide nanofibers. Heparan-sulfate-mimicking functional groups on this scaffold provide a close similarity to permissive elements of neural ECM where laminin interacts with HSPG. Full-length lamininHSPG complexes were shown to be more effective in neurite outgrowth when compared to laminin alone. In accordance with this finding, heparan-sulfate-mimicking moieties and laminin-derived epitopes presented on PA nanofibers were analyzed to find any cooperative work in neurite outgrowth process resulting in a more effective neural induction when compared to these epitopes alone. In addition, cells cultured on these PA scaffolds were analyzed under inhibitory conditions provided by chondroitin sulfate proteoglycans (CSPGs) in order to find any effect of PA nanofibers in overcoming inhibition of axonal growth. Inhibition of axonal regeneration by extracellular environmental elements in CNS is the main problem leading to poor regeneration after any damage to CNS and overcoming this barrier is a promising approach for therapy.

\section{Experimental}

\subsection{Materials}

9-fluorenylmethoxycarbonyl (Fmoc) and tert-butoxycarbonyl (Boc) protected amino acids, [4-[ $\alpha$ - $\left(2^{\prime}, 4^{\prime}\right.$-dimethoxyphenyl)Fmocaminomethyl]enoxy]acetamidonorleucyl-MBHA resin (Rink amide MBHA resin), Fmoc-Asp(OtBu)-Wang resin and 2-(1H-Benzotriazol-1-yl)-1,1,3,3-tetramethyluronium hexafluorophosphate (HBTU) were purchased from NovaBiochem and ABCR. The other chemicals were purchased from Fisher, Merck, Alfa Aesar or Aldrich. NGF was purchased from Thermo Scientific (RP-86969). Poly-D-Lysine (PDL) and collagen type I (C7661) were purchased from Sigma. Chondroitin sulfate proteoglycan mixture (CSPG) was purchased from Millipore (CC117). Live/Dead Assay (L3224) and other cell culture materials were purchased from Invitrogen. Proliferation assay was purchased from Roche (11647229001). Antibodies and reagents for ELISA assay were purchased from R\&D.

\subsection{Synthesis of peptide amphiphiles (PA)}

PAs were constructed on Rink Amide MBHA resin or Fmoc$\mathrm{Glu}(\mathrm{OtBu})$-Wang resin. Amino acid couplings were performed with two equivalents of Fmoc protected amino acid, 1.95 equivalents HBTU and three equivalents of N,N-diisopropylethylamine (DIEA) for $2 \mathrm{~h}$. Fmoc removal was performed with $20 \%$ piperidine/dimethylformamide solution (DMF) for $20 \mathrm{~min}$. 10\% acetic anhydride solution in DMF was used to block remaining free amine groups after amino acid coupling. After each step, resin was washed with $3 \times$ DMF, $3 \times$ DCM and $3 \times$ DMF, respectively. Sulfobenzoic acid was added to the side chain of lysine to synthesize sulfonated PAs. A lysine residue with 4-methytrityl (Mtt) side chain protection was used for selective deprotection of amine groups. Mtt removal was performed by shaking resins for 5 min with TFA:TIS: $\mathrm{H}_{2} \mathrm{O}: \mathrm{DCM}$ in the ratio of $5: 2.5: 2.5: 90$. Cleavage of the PAs from the resin was carried out with a mixture of TFA:TIS: $\mathrm{H}_{2} \mathrm{O}$ in the ratio of $95: 2.5: 2.5$ for $2 \mathrm{~h}$. Excess TFA was removed by rotary evaporation. The remaining viscous PA solution was triturated with ice-cold ether and the resulting white precipitate was dried under vacuum. PAs were characterized by liquid chromatography-mass spectrometry (LC-MS). Mass spectrum was obtained with Agilent LC-MS equipped with Agilent 6530 Q-TOF with an ESI source and Zorbax Extend-C18 $2.1 \times 50 \mathrm{~mm}$ column for basic conditions and Zorbax SB-C8 $4.6 \mathrm{~mm} \times 100 \mathrm{~mm}$ column for acidic conditions. A gradient of (a) water $\left(0.1 \%\right.$ formic acid or $\left.0.1 \% \mathrm{NH}_{4} \mathrm{OH}\right)$ and (b) acetonitrile ( $0.1 \%$ formic acid or $0.1 \% \mathrm{NH}_{4} \mathrm{OH}$ ) was used. In order to purify the peptides, Agilent preparative reverse-phase HPLC system equipped with Zorbax Extend-C18 $21.2 \times 150 \mathrm{~mm}$ column was used for basic conditions and Zorbax SB-C8 $21.2 \times 150 \mathrm{~mm}$ column was used for acidic conditions. A gradient of (a) water $\left(0.1 \%\right.$ TFA or $\left.0.1 \% \mathrm{NH}_{4} \mathrm{OH}\right)$ and (b) acetonitrile ( $0.1 \%$ TFA or $\left.0.1 \% \mathrm{NH}_{4} \mathrm{OH}\right)$ was used.

\subsection{SEM imaging of PA nanofiber matrices}

PA nanofiber networks were observed by imaging with a scanning electron microscope (SEM). Oppositely charged PA solutions (1 wt\%) were mixed in appropriate volume ratio (final volume being $50 \mu \mathrm{l}$ ) to produce gels with neutral charge. Gels were transferred to metal mesh and dehydrated by transferring to $20 \%, 40 \%$, $60 \%, 80 \%$ and $100 \% \mathrm{v} / \mathrm{v}$ ethanol sequentially. They were criticalpoint-dried afterwards by using Autosamdri ${ }^{\circledR}-815 \mathrm{~B}$ equipment from Tousimis. Dried PA gels were coated with $9 \mathrm{~nm} \mathrm{Au} / \mathrm{Pd}$ and SEM (FEI Quanta 200 FEG) images were taken by using an Everhart-Thornley Detector (ETD) at high vacuum mode with $15 \mathrm{keV}$ beam energy.

\subsection{AFM imaging of PA nanofiber matrices}

PA nanofibers were also observed by imaging with atomic force microscopy (AFM). Oppositely charged PA solutions (0.04 wt.\%) were mixed in appropriate volume ratios (final volume being $100 \mu \mathrm{l})$ to produce nanofibers with neutral charge. PA solutions were drop-cast onto a $1 \mathrm{~cm}^{2}$ silicon wafer. After $1 \mathrm{~min}$, solvent on the wafer was removed by using dust-free tissue paper, and the rest was air-dried. Non-contact mode AFM was performed by using model MFP-30 from Asylum Research. Resonance frequency and spring constant of AFM tips used in this study were $150 \mathrm{kHz}$ and $5 \mathrm{~N} \mathrm{~m}^{-1}$, respectively. All images were taken with a $0.5-1 \mathrm{~Hz}$ scan rate. 


\subsection{Circular dichroism}

A JASCO J815 CD spectrometer was used at room temperature. Oppositely charged $2.5 \times 10^{-4} \mathrm{M}$ PA solutions were mixed in appropriate volume ratios (final volume being $500 \mu \mathrm{l}$ ) to produce nanofibers with net neutral charge. Measurements were carried out from $300 \mathrm{~nm}$ to $190 \mathrm{~nm}$, data interval and data pitch being $0.1 \mathrm{~nm}$, and scanning speed being $100 \mathrm{~nm} \mathrm{~min}{ }^{-1}$, all measurements with three accumulations. Digital Integration Time (DIT) was selected as $1 \mathrm{~s}$, band width as $1 \mathrm{~nm}$, and the sensitivity was standard.

\subsection{Oscillatory rheology}

Oscillatory rheology measurements were performed with Anton Paar Physica RM301 Rheometer operating with a $25 \mathrm{~mm}$ parallel plate configuration at $25^{\circ} \mathrm{C}$. Each sample of $250 \mu \mathrm{l}$ total volume with a final PA concentration of $1 \mathrm{wt}$ \% and equimolar concentrations of each PA component was carefully loaded onto the center of the lower plate and incubated for $10 \mathrm{~min}$ before measurement. After equilibration, the upper plate was lowered to a gap distance of $0.5 \mathrm{~mm}$. Storage moduli $\left(G^{\prime}\right)$ and loss moduli $\left(G^{\prime \prime}\right)$ values were scanned from $100 \mathrm{rad} \mathrm{s}^{-1}$ to $0.1 \mathrm{rad} \mathrm{s}^{-1}$ of angular frequency, with a $0.5 \%$ shear strain. Three samples were measured for each PA gel.

\subsection{PC-12 neurite extension assay}

Equal volumes of 1.5 mM HSM-PA and IKVAV-PA and appropriate concentrations of Glu-PA and Lys-PA were used to form gels with neutral charge in 96-well plates. For instance, to form HSMPA/Lys-PA gel, equal volumes of $1.5 \mathrm{mM}$ HSM-PA was mixed with $4.5 \mathrm{mM}$ of Lys-PA in order to neutralize the charge. PA-gel coated plates were incubated at $37^{\circ} \mathrm{C}$ for $30 \mathrm{~min}$, prior to overnight incubation in laminar flow hood at room temperature for solvent evaporation. The next day, PA matrix formed on 96-well plates was UV sterilized and PC-12 cells $\left(5 \times 10^{3}\right.$ cells per well) were cultured on these matrices or $0.01 \mathrm{wt} . \%$ Collagen I, which was used as a positive control. By addition of cells in culture media to PA-coated surfaces, rehydration of the matrix forms a thin gel adhered to the culture surface. Roswell Park Memorial Institute medium (RPMI) with $10 \%$ horse serum (HS), $5 \%$ fetal bovine serum (FBS), 2 mM L-Glutamine and $1 \%$ Penicillin/Streptomycin $(\mathrm{P} / \mathrm{S})$ was used as culture medium. The day after seeding cells, media over cells were changed with neural induction medium consisting of MEM with $2 \%$ HS, $1 \%$ FBS, $2 \mathrm{mM}$ L-Glutamine and $1 \% \mathrm{P} / \mathrm{S}$ along with $20 \mathrm{ng} \mathrm{ml}^{-1}$ NGF. A week after inducing cells with NGF, optical images were taken at three random points of each well at $200 \times$ magnification. Total neurite length in each image was quantified by Image $J$ and normalized by cell number/image. Average neurite length was obtained from three replicate wells for each coating material. In order to obtain another measure for quantification of neurite inducing potentials of PA nanofibers, neurite extending cells were counted in the same images by Image $J$ and percentage of cells with neurites was calculated. Cellular extensions with at least one cell body length were considered as neurite for quantifications. Results were evaluated by one-way ANOVA for statistical significance.

\subsection{Live/dead assay}

96-well plates were coated with PA matrices and 0.1\% PDL as described above in neurite extension assay protocol. $5 \times 10^{3}$ cells/well were seeded and cultured in culture media described above for three days. Live/Dead assay (Invitrogen) was carried out by treating cells with $2 \mu \mathrm{M}$ Calcein AM and $2 \mu \mathrm{M}$ Ethidium homodimer I (EthD-1) for $30 \mathrm{~min}$ at room temperature (RT). After incubation, images were taken at four random points per well with a fluorescent microscope at $200 \times$ magnification. All samples were studied in triplicate. Live (stained green by Calcein AM metabolization) and dead (stained red by EthD-1 internalization) cells were counted by using Image $\mathrm{J}$ and live cell percentage was calculated for each sample. Results were evaluated by one-way ANOVA for statistical analysis.

\subsection{Proliferation assay}

PC-12 cells were seeded on PA coated wells of a 96-well plate $\left(3 \times 10^{3}\right.$ cells per well) and cultured either in culture medium (indicated as no induction) or in induction medium (with NGF, indicated as neural induction). Colorimetric BrdU assay (Roche) was used for the determination of proliferative activity of cells at day 7. Cells were treated with BrdU overnight and fixed. Peroxidase labeled anti-BrdU antibody was used for labeling BrdU incorporated cells that were proliferating. After adding colorimetric peroxidase substrate, absorbance values were measured at $370 \mathrm{~nm}$. All samples were studied in triplicate. Results were evaluated by two-way ANOVA for statistical significance.

\subsection{SEM imaging of PC-12 cells on PA nanofiber matrices}

$13 \mathrm{~mm}$ glass coverslips placed in 24-well plates were coated with equimolar concentrations of PA solutions as described above. $3 \times 10^{4}$ cells were seeded per well and cells were induced for neural differentiation a day later with neural induction medium containing $20 \mathrm{ng} \mathrm{ml}^{-1} \mathrm{NGF}$. Three days after induction, cells were washed with PBS and fixed at RT with $2 \%$ gluteraldehyde and $1 \%$ $\mathrm{OsO}_{4}$ for $1 \mathrm{~h}$ each, respectively. Samples were washed with PBS after fixation and dehydrated by transferring to $20 \%, 40 \%, 60 \%$, $80 \%$ and $100 \% \mathrm{v} / \mathrm{v}$ ethanol, sequentially. They were critical-pointdried afterwards by using Autosamdri ${ }^{\circledR}-815 \mathrm{~B}$ from Tousimis. Dried samples were coated with $6 \mathrm{~nm} \mathrm{Au} / \mathrm{Pd}$ and SEM (FEI Quanta 200 FEG) images were taken by using an ETD detector at high vacuum mode with $30 \mathrm{keV}$ beam energy.

\subsection{CSPG inhibition assay}

CSPG solution was mixed with negatively charged PA solutions or Collagen I and PDL at concentrations that resulted in $1 \mu \mathrm{g}$ CSPG cm$~^{-2}$. 96-well plate wells were coated with PA gels, Collagen I and PDL as described above, with (labeled as CSPG + ) or without (labeled as CSPG-) CSPG. PC- 12 cells $\left(5 \times 10^{3}\right.$ cells per well) were seeded in culture medium and induced for neural differentiation the next day with neural induction medium containing $20 \mathrm{ng} \mathrm{ml}^{-1} \mathrm{NGF}$. Quantifications were carried out from optical images taken on day 2 after induction by Image $\mathrm{J}$ as described in the neurite extension assay protocol above. Results were evaluated by two-way ANOVA for statistical analysis.

\subsection{Immunocytochemistry}

$13 \mathrm{~mm}$ glass coverslips placed in 24-well plates were coated with equimolar concentrations of PA solutions as described above. $3 \times 10^{4}$ PC-12 cells were seeded per well and cells were induced for neural differentiation a day after with neural induction medium containing $20 \mathrm{ng} \mathrm{ml}^{-1} \mathrm{NGF}$. Seven days after neural induction, cells were fixed with $4 \%$ paraformaldehyde in PBS for $15 \mathrm{~min}$ at RT and permeabilized with permeabilization buffer (0.5 wt.\% NP40, $10 \mathrm{mM}$ Tris- $\mathrm{HCl} \mathrm{pH} 7.5$ and $0.2 \mathrm{mM} \mathrm{ZnCl}_{2}$ ) for $15 \mathrm{~min}$ at RT. After washing with PBS, blocking was carried out with $10 \%$ goat serum and $1 \%$ bovine serum albumin (BSA) in PBS with $0.3 \%$ Triton-X for $30 \mathrm{~min}$ at RT. Cells were then treated with primary antibodies against Synaptophysin I (mouse monoclonal, Millipore) at 1:400 dilution and incubated overnight at $4{ }^{\circ} \mathrm{C}$. After washing with PBS several times, cells were incubated with $\mathrm{Cy} 2$ conjugated goat 
a.

$b$.
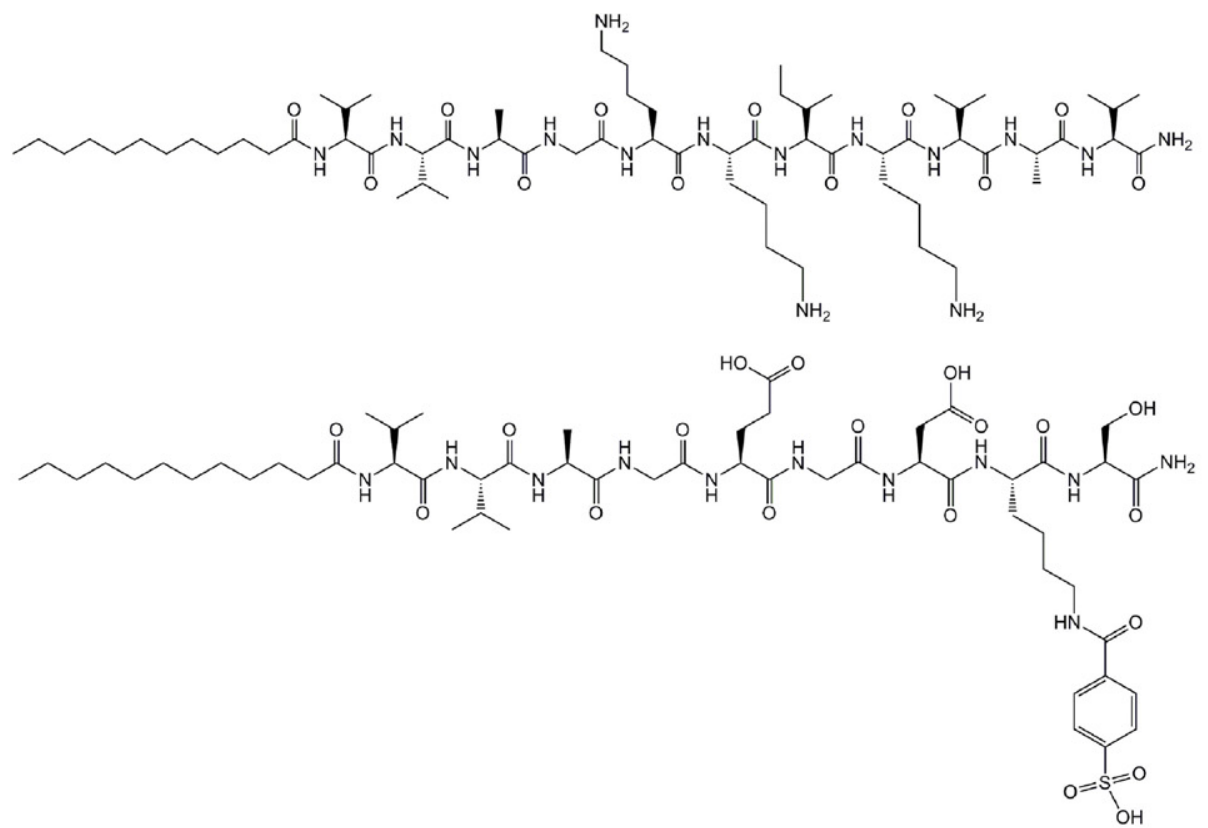

c.
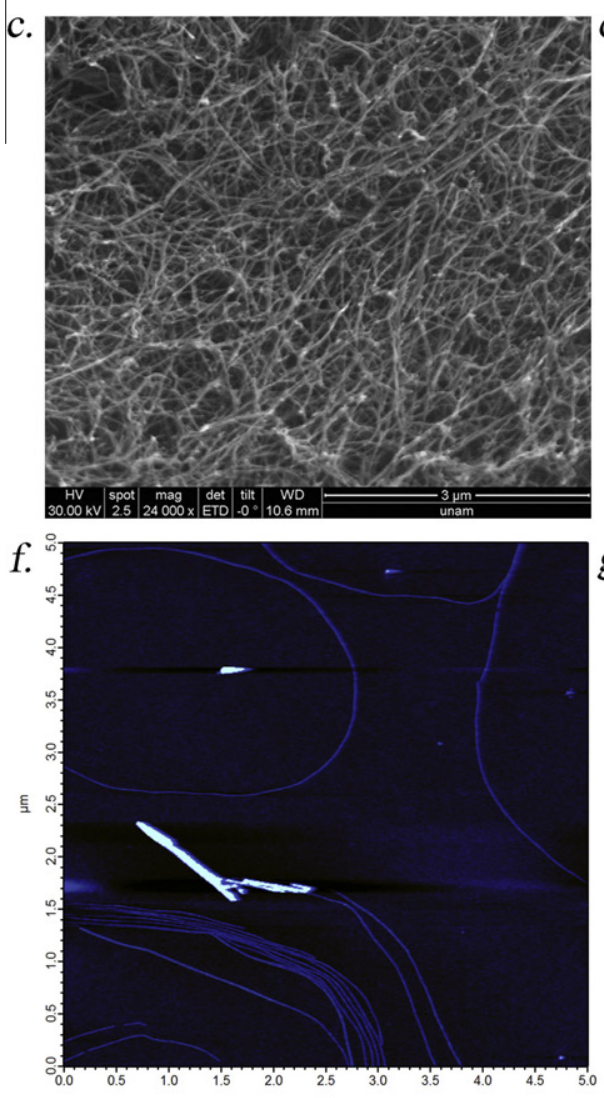

um
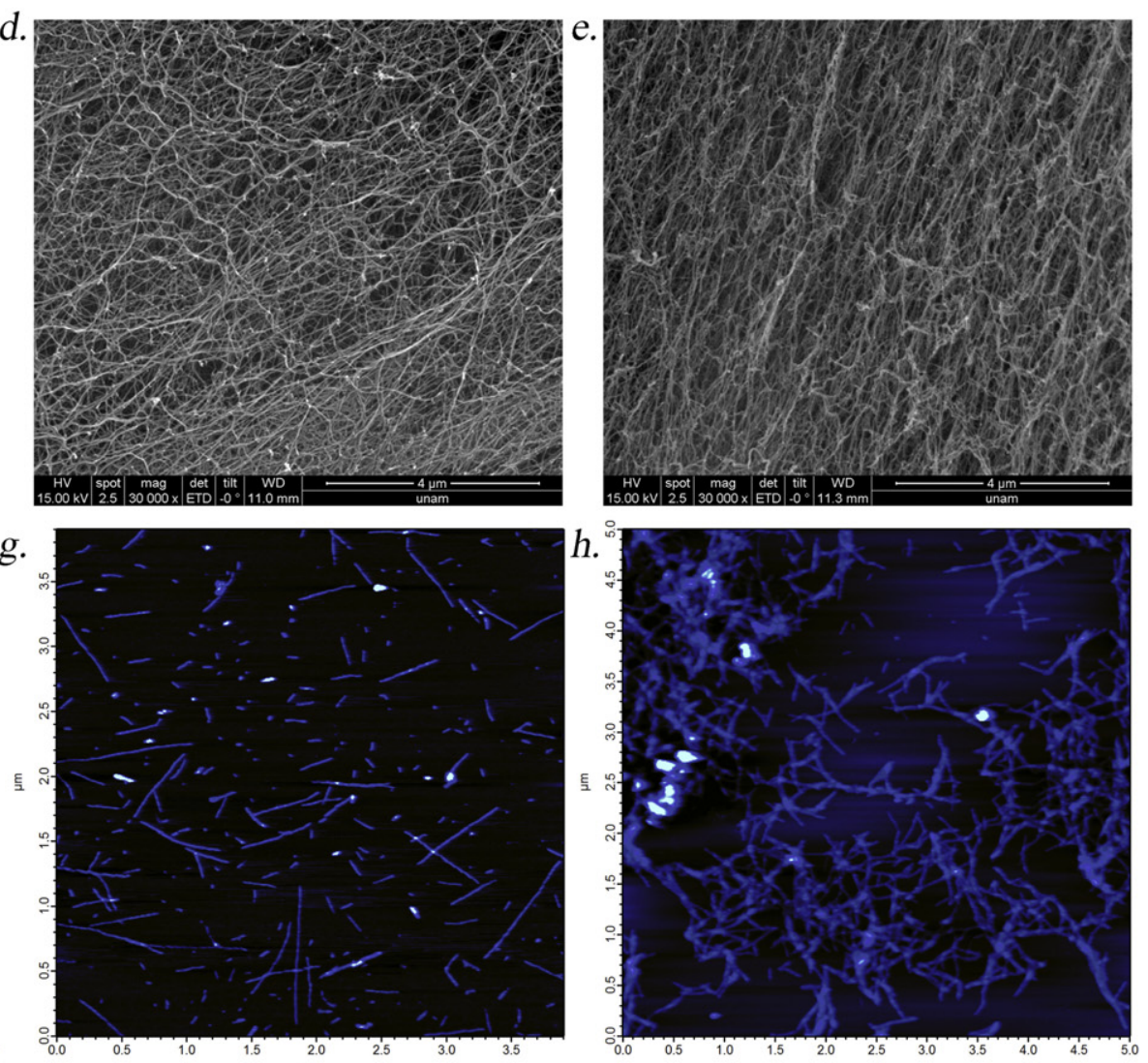

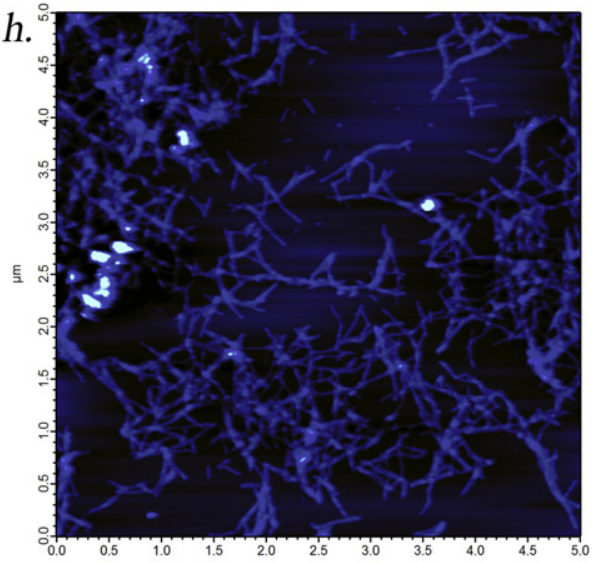

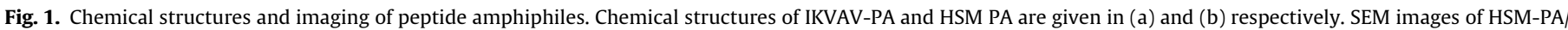

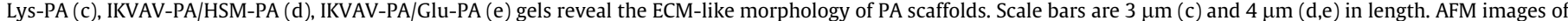
HSM-PA/Lys-PA (f), IKVAV-PA/Glu-PA (g), IKVAV-PA/HSM-PA (h) show nanofibers formed by peptide amphiphiles.

anti-mouse secondary antibody for $1 \mathrm{~h}$ at RT. To counter-stain nuclei, cells were incubated with $1 \mu \mathrm{M}$ TO-PRO-3 (Invitrogen) in PBS for $15 \mathrm{~min}$ at RT after which they were washed with PBS several times. Coverslips were then mounted with Prolong Gold Antifade Reagent (Invitrogen) and sealed with nail polish. Samples were imaged with confocal microscopy (Zeiss LSM510).

\subsection{NGF release assay by ELISA}

500 ng NGF was encapsulated into IKVAV-PA/Glu-PA $(n=5)$ or IKVAV-PA/HSM-PA $(n=4)$ gels. Molar ratios of PAs were adjusted to neutralize the final charge, similar to cell culture experiments. $25 \mu \mathrm{l}$ of positively charged PA (IKVAV-PA) was mixed with $1 \mu \mathrm{l}$ 


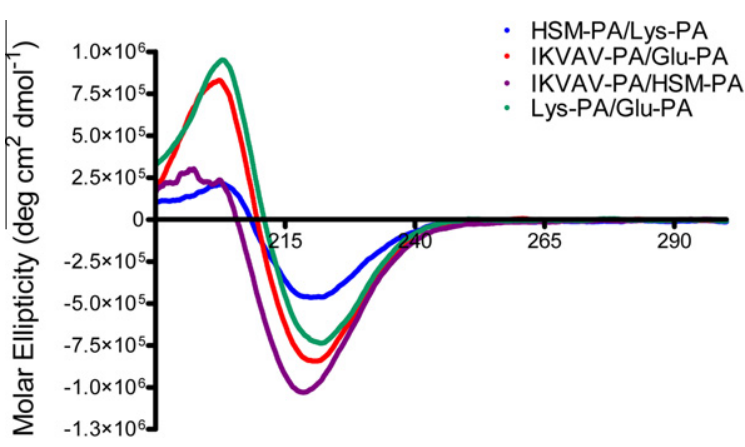

Fig. 2. Characterization of secondary structure of peptide amphiphiles by CD. All PA combinations were found to contain beta-sheet secondary structure by circular dichroism analysis.

NGF (500 ng) and then $25 \mu \mathrm{l}$ from either of HSM-PA or Glu-PA was added to induce gel formation. After $30 \mathrm{~min}$ incubation at $37{ }^{\circ} \mathrm{C}$ for a stable gel formation, $250 \mu \mathrm{l}$ PBS was added carefully without disturbing the gel at the bottom of tubes. For measurement of NGF release, $200 \mu$ l PBS over gels were collected at different time points ( $3 \mathrm{~h}, 2.5$ days, 5 days and 10 days) while the same volume of fresh buffer was added carefully. NGF ELISA (R\&D Systems) was performed according to the manufacturer's instructions to detect NGF concentration in these samples.

\section{Results and discussion}

\subsection{Peptide amphiphile design and characterization}

In order to study the neurite-outgrowth-supporting ability of a novel peptide amphiphile scaffold containing heparan sulfate and laminin-derived epitopes, four different peptide amphiphile molecules were designed and synthesized. All PA molecules had a hydrophobic alkyl tail consisting of lauric acid and a $\beta$-sheet forming peptide sequence, VVAG. This sequence consists of four nonpolar amino acid residues, among which valine has a very high beta sheet-forming propensity provided by its hydrophobic side chain while glycine is used as a spacer between the hydrophobic part of the sequence and hydrophilic epitope region $[27,28]$. Lauryl-VVAGIKVAV-Am (IKVAV-PA) was designed as a laminin mimetic PA molecule, since IKVAV epitope was previously shown to induce differentiation of neural progenitor cells into neurons [24] (Fig. 1a). Lauryl-VVAGEGDK(pbs)S-Am (HSMPA) was developed to mimic heparan sulfates with its sulfonate, hydroxyl and carboxylic acid groups incorporated as amino acid side chains (Fig. 1b). This molecule was shown to have affinity for heparin binding growth factors [29]. IKVAV-PA/HSM-PA scaffolds consisted of the two bioactive PAs, laminin-derived IKVAV-PA and HSM-PA. The other two PA molecules that we have used were Lauryl-VVAGE (Glu-PA) and Lauryl-VVAGK-Am (Lys-PA) (Fig. S2a and b). These two PAs did not bear a bioactive epitope sequence and they were used for gel formation with oppositely charged PAs to obtain HSM-PA/Lys-PA and IKVAV-PA/ Glu-PA nanofibers. Lys-PA/Glu-PA nanofibers were used as nonbioactive gel control having the nanofibrous structure without any bioactive functional groups. The PA molecules were synthesized by solid phase peptide synthesis, purified with HPLC and characterized by LC-MS (Fig. S1). AFM images taken for each PA combination showed that all these combinations formed nanofibers whose lengths ranged from a few hundred nanometers to several microns (Figs. $1 \mathrm{f}-\mathrm{h}$ and S2d). Also bundling of individual nanofibers can be observed for each combination. The SEM imaging of nanofiber networks in PA gels (Figs. 1c-e and S2c) revealed morphological similarity of nanofibrous PA scaffolds to natural

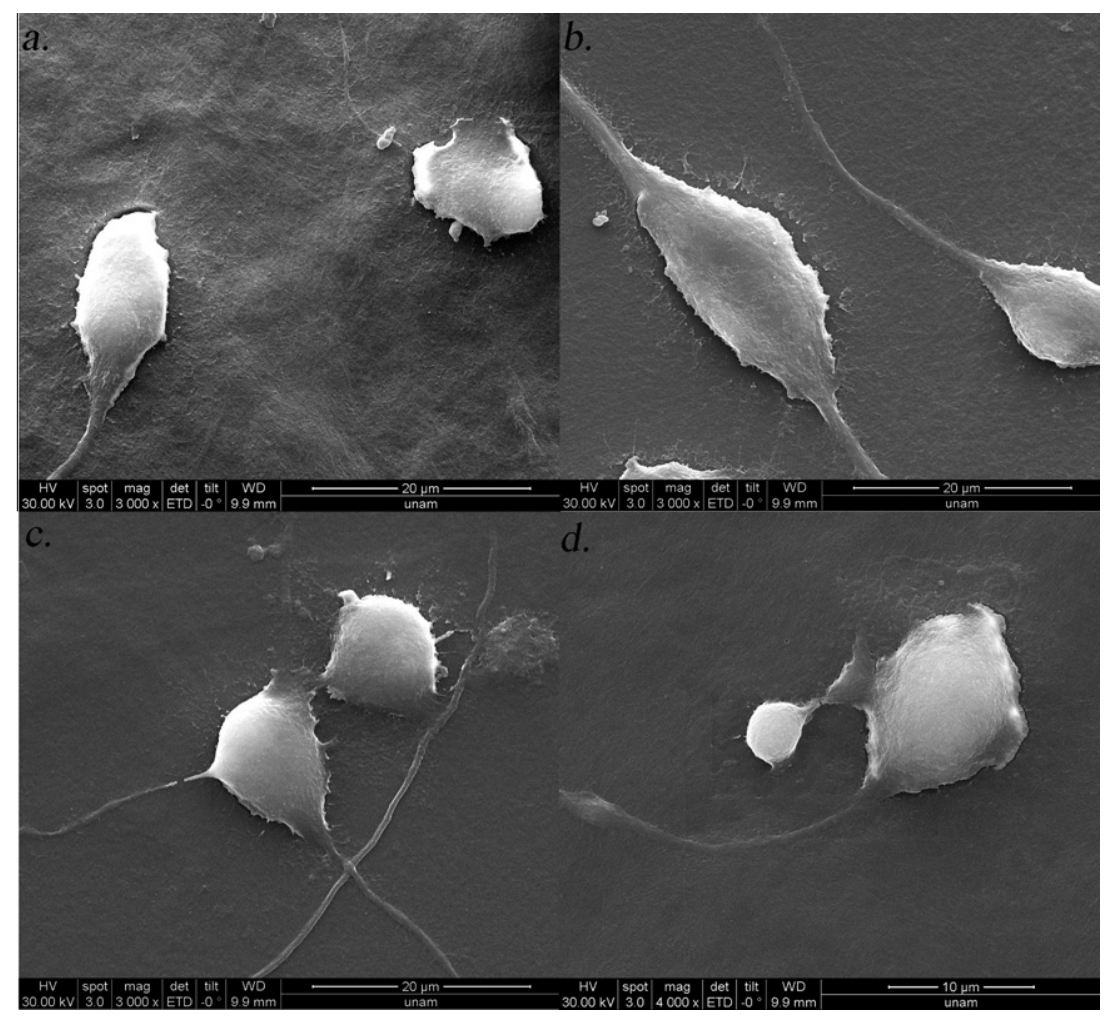

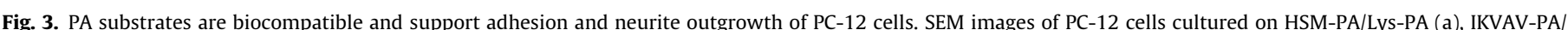

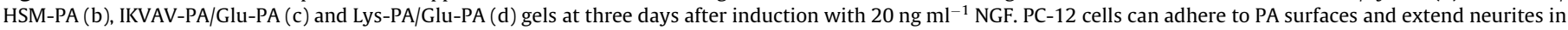
the presence of NGF. Scale bars are $20 \mu \mathrm{m}(\mathrm{a}-\mathrm{c})$ and $10 \mu \mathrm{m}(\mathrm{d})$ in length. 
ECM that surrounds the cells in tissues [30]. Neural ECM is quite different in developing and mature CNS tissues in terms of the contents and physical structure. Fibrous proteins having important roles in nervous tissue development, especially as guidance molecules are down-regulated during maturation, leading to an ECM with low content of fibrous structures [31]. PA scaffolds used here resemble embryonic ECM of neural tissues in terms of physical appearance of fibrous networks. As neural regeneration involves new tissue formation as well as guidance of nerve terminals for appropriate formation of neural networks in regenerated tissue similar to developmental processes, such a physical similarity can be speculated to improve the effectiveness of the PA nanofibers used in this study. We employed a circular dichroism spectrophotometer and observed predominant $\beta$-sheet structures forming the nanofibers (Fig. 2). Since mechanical properties of the ECM are crucial for neuritogenesis, we utilized oscillatory rheology to study mechanical properties of the PA gels. Due to technical limitations, gels measured with rheology are not prepared with the same methods as those used in cell culture experiments. PA gels used for cell culture experiments are quite thin after rehydration with cell culture media, which limits measurement with oscillatory rheology. Since the mechanical properties of the thin (rehydrated) gels used in the cell culture experiments might differ from that of the bulk gels whose oscillatory rheology data are provided in Fig. S3, care must be taken in interpreting these results accordingly. Rheology results confirmed that these materials formed gels as the storage moduli of all PA combinations were higher than their loss moduli. Storage moduli of PA gels used in this study, which refer to the stiffness of materials, indicated similar properties to soft tissues such as the neural tissue (Fig. S3). Neural tissues such as the brain are soft tissues, as indicated by measurement of rat brain's shear modulus as $330 \pm 100 \mathrm{~Pa}$ [32]. Although this measurement was carried out under $2 \%$ oscillatory strain, we carried out PA gel measurements under $0.5 \%$ oscillatory strain, which is a more appropriate value, confined in the linear viscoelastic (LVE) range, for this kind of materials. At higher values measurement drifts away from the LVE range and breaks the gel, thus giving lower stiffness values. These PA gels are hence suitable to be used as scaffolds for neural cells and in vivo applications for neuroregeneration studies in terms of their mechanical properties when used in the same conditions tested in oscillatory rheology measurements [33-35].

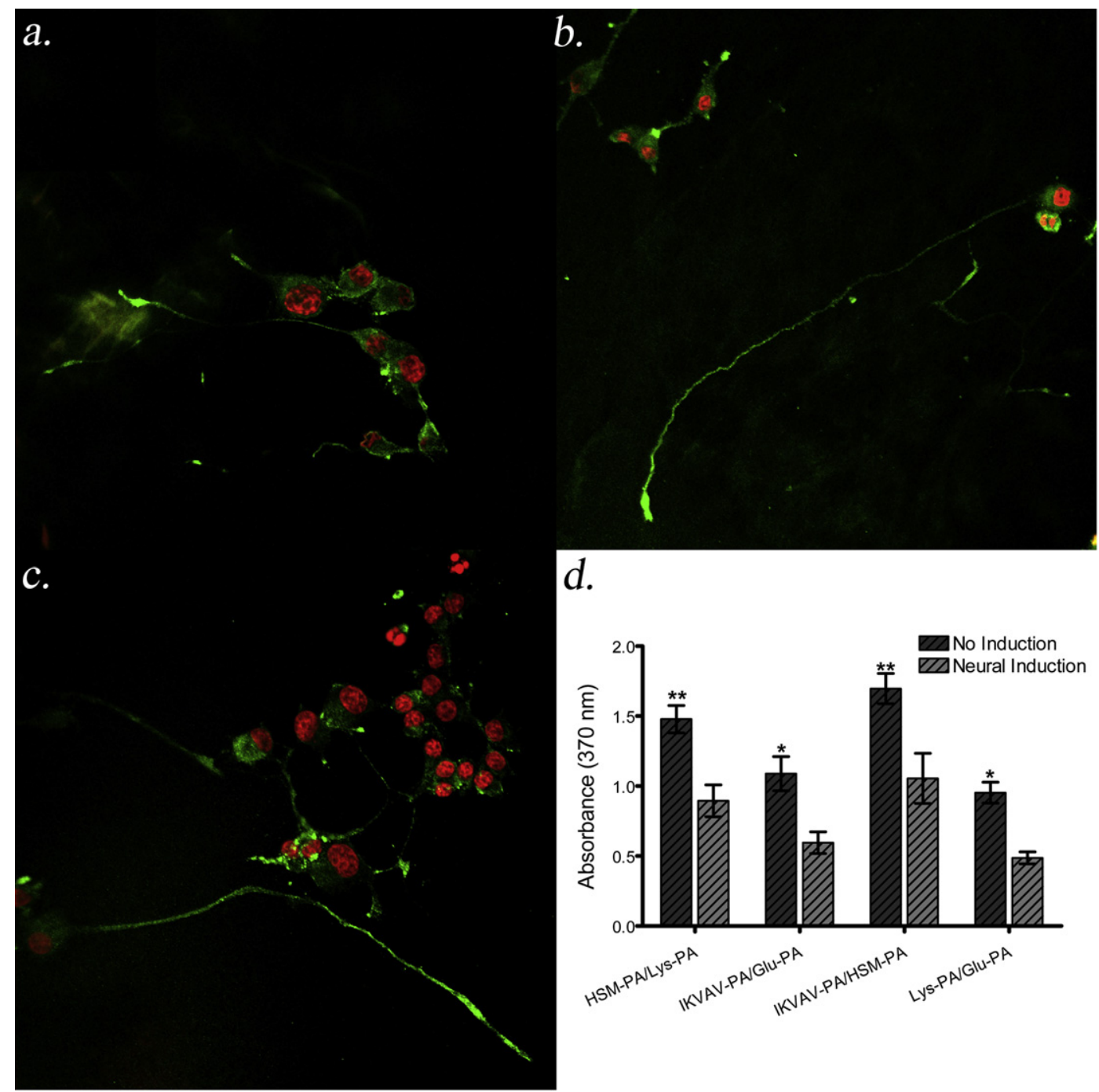

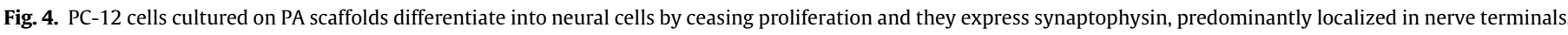

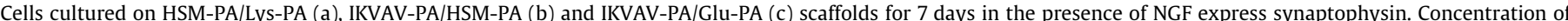

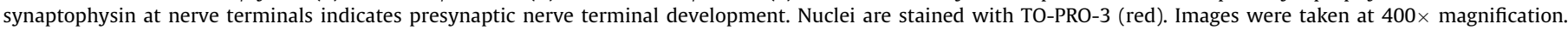
Proliferation assay at day 7 (d) verified the neural differentiation on these PA scaffolds as proliferation was reduced in cells treated with NGF. 


\subsection{Neural differentiation of PC-12 cells on PA scaffolds}

In order to determine the neurite-outgrowth-promoting effect of the PA nanofibers, PC-12 cells were used. PC-12 is a cell line derived from rat adrenal gland pheochromocytoma and it is a commonly used model system to determine effects of different molecules on neural differentiation and axonal growth as these cells can be induced to terminally differentiate into neural cells in the presence of NGF [36,37]. Materials developed for neuroregenerative purposes should promote neurite outgrowth, since it is an essential step in making functional synapses, which is crucial in neuroregeneration. In the nervous system, neurite outgrowth takes place through the collaborative effort of a number of soluble factors and cell adhesion molecules as well as extracellular matrix elements. Herein, we combined mimics of two neural ECM components, laminin and heparan sulfate, which were previously shown to promote axonal growth and neurite outgrowth when used in combination $[18,19,38]$. In order to analyze the biocompatibility of PA scaffolds, we assessed the viability of the PC-12 cells cultured on IKVAV-PA/HSM-PA, IKVAV-PA/Glu-PA, HSM-PA/Lys-PA and LysPA/Glu-PA scaffolds. As a result of live/dead assays, we observed that cells behaved similarly on all PA substrates as well as PDL, which shows that all PA combinations were biocompatible (Fig. S4). Since PC-12 cells are suspension cells and need to adhere to a substrate in order to differentiate, the affinity of these cells to PA substrates was analyzed. Similar to collagen, PA substrates induced adherence of PC- 12 cells. In addition, cells could extend neurites on these surfaces after NGF addition, as can be seen in the SEM images of cells on PA scaffolds (Fig. 3a-d).

Neuroprogenitor cells in early developmental stages have mitotic activity, while during late stages of neural development they exit from the cell cycle and cease proliferation as they start to differentiate [39]. Hence, ceasing proliferation is an indication of differentiation for neural cells as terminally differentiated neurons do not proliferate. In order to analyze the proliferation profile of PC-12 cells on PA scaffolds, BrdU assay was carried out 1 week after neural induction with NGF. Proliferation was found to diminish on all PA surfaces as determined by BrdU assay, indicating induction of neural differentiation (Fig. 4d).

As additional evidence of neural differentiation and maturation, cells cultured on all PA combinations were found to express Synaptophysin I revealed by immunostaining (Figs. 4a-c and S5). Synaptophysin I is the most abundant synaptic protein at presynaptic nerve terminals having a role in synaptic vesicle endocytosis [40]. Localization of synaptophysin in axonal protrusions by transportation from the cell body along the elongated axon is an indication of presynaptic nerve terminal development [41]. Expression of synaptophysin was observed to be localized heavily on the nerve terminals of the differentiated PC-12 cells on PA substrates, indicating the presynaptic nerve terminal development and synaptic potential of these cells.

In order to analyze the effect of neural ECM mimetic peptide nanofibers on neural differentiation, we also measured lengths of neurites produced by PC-12 cells. Measurement of neurite length during NGF treatment provides quantitative information about neural differentiation [42]. Neurite lengths that were measured a week after neural induction pointed out IKVAV-PA/HSM-PA nanofibers as the most potent neurite inducer scaffold. Neurites on this scaffold were found to be significantly longer when compared to those on IKVAV-PA/Glu-PA and HSM-PA/Lys-PA nanofibers (Figs. 5a and S6). Besides, significantly higher number of cells could extend neurites on IKVAV-PA/HSM-PA nanofibers when compared to non-bioactive Lys-PA/Glu-PA scaffold (Fig. 5b). IKVAV-PA/HSMPA scaffold was the only bioactive scaffold on which the number of cells extending neurites was significantly different from the control PA scaffold. Although the number of cells with neurites
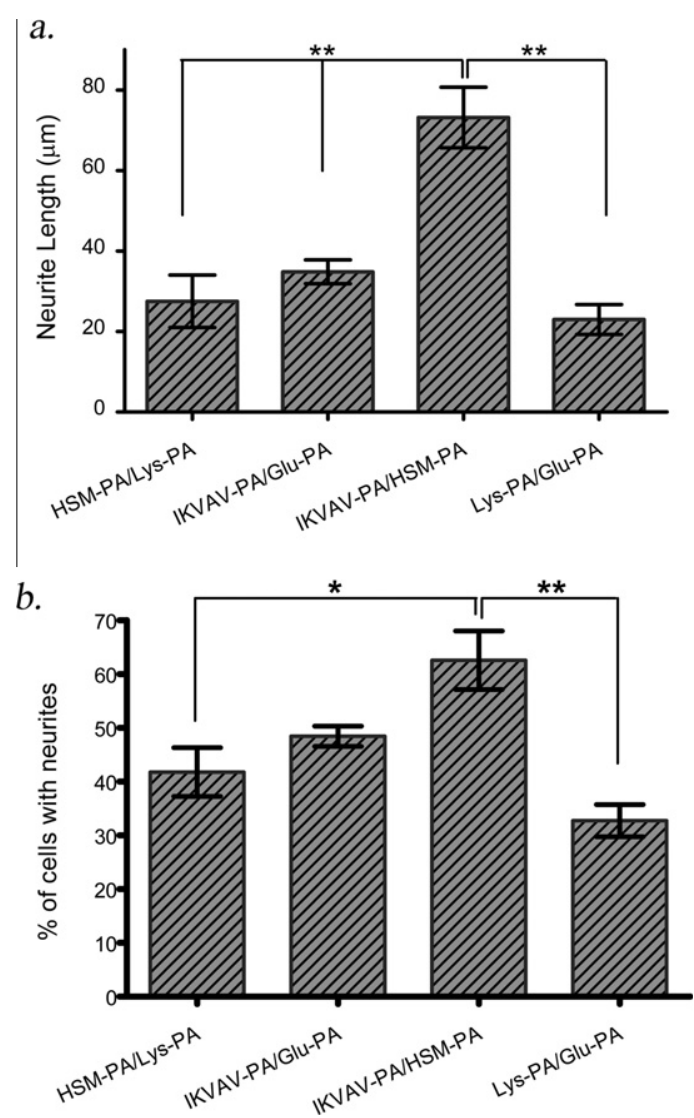

Fig. 5. Combination of HS and laminin epitopes supports extension of much longer neurites. Neurite length (a) and percentage of neurite bearing cells (b) quantified by Image J at day 7 after induction reveals the IKVAV-PA/HSM-PA combination as the most suitable PA scaffold for neurite outgrowth.

cultured on IKVAV-PA/Glu-PA and HSM-PA/Lys-PA scaffolds was higher than those on non-bioactive Lys-PA/Glu-PA scaffold, the differences were not statistically significant.

These results indicate that the presence of both laminin-mimic and heparan-sulfate-mimic molecules enhance each other's abilities to induce neural differentiation and synthetic PA scaffolds with both laminin and heparan-sulfate-derived signals on the surface can successfully mimic the natural system in the neural ECM.

\subsection{Investigation of NGF/HSM-PA interaction}

Laminin-derived epitope acts through interacting with cells via integrin receptors. Heparan sulfates induce differentiation of cells by interacting with growth factors, and we have previously shown that HSM-PA interacts with vascular endothelial growth factor, inducing differentiation of endothelial cells [41]. Since our results showed that IKVAV-PA/HSM-PA nanofibers act as a potential dual promoter of neurite growth, we investigated whether HSM-PA's role in this system was through its interaction with NGF, which is the main growth factor that is responsible for neural differentiation. NGF is endogenously expressed in other tissues outside CNS with varying levels depending on the amount of nervous tissue in the tissue. It was previously found that such tissues contain NGF amounts ranging from $1.0 \pm 0.1 \mathrm{ng} \mathrm{g}^{-1}$ of the wet organ (heart atriatum) to $25 \pm 4 \mathrm{ng} \mathrm{g}^{-1}$ (superior cervical ganglia) in rat tissues depending on the innervation level [43]. NGF is also used in peripheral nerve regeneration studies and found to have optimum regenerative activity when used at a concentration of $800 \mathrm{pg}^{-1}$ in rat sciatic nerve injury model [44]. 


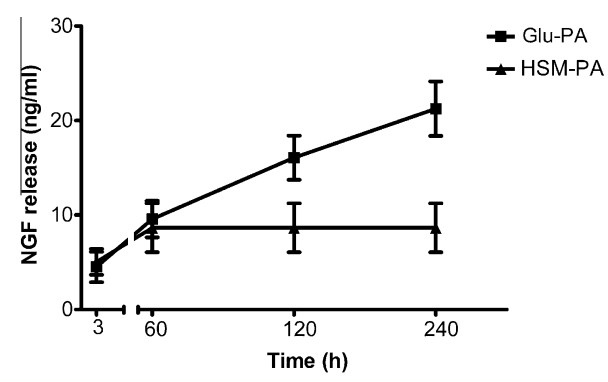

Fig. 6. Time-dependent NGF release from different PA gel systems. HSM-PA confers advantage in terms of growth factor binding to the gel system it is included. IKVAVPA/HSM-PA and IKVAV-PA/Glu-PA were compared. NGF concentration released from gels were determined with ELISA method.

Effective binding of NGF to heparan sulfate or heparin was shown previously $[21,45]$. The nanofibers formed by HSM-PA molecules contain an abundant number of functional groups presented on the surface and can provide affinity to NGF. NGF release assay was performed to assess the release rate of the NGF from PA nanofibers, which indirectly gives information about NGF's affinity with this three-dimensional nanofiber network comprising PA gels. As shown in Fig. 6, growth factors encapsulated within the PA gel system were released in the same rate from both IKVAV-PA/Glu-PA and IKVAV-PA/HSM-PA gels at earlier time points. The released amount of NGF was low for both gels because NGF could be wrapped up in fiber bundles during the process of nanofiber network formation. This physical entrapment might have delayed the release of growth factors, even though they don't have strong affinity to individual nanofibers. Since we performed this assay in a buffer system, no enzymatic degradation was possible. The dynamic nature of the PA nanofiber system should allow the slow release of NGF physically in a time-dependent manner. Timedependent linear increase of NGF release from control PA gel (IKVAV-PA/Glu-PA) supports this notion. Release from IKVAV-PA/
HSM-PA gel ceased after 2.5 days. It is reasonable to assume that growth factors bound to the nanofiber network were not released during this time period. Oppositely, release from IKVAV-PA/Glu-PA gels proceeds linearly until 10 days, where the experiment was ended. These data show that IKVAV-PA/HSM-PA gel network interacts with NGF with higher affinity than IKVAV-PA/Glu-PA gel, which can be attributed to the functional groups presented on HSM-PA nanofibers. As a result, we suggest that heparan-sulfatemimicking chemical groups on the surface of the nanofibers effectively present NGF to cell surface receptors while IKVAV epitopes induce neurite outgrowth through integrin signaling, simultaneously leading to a more effective neurite outgrowth.

\subsection{Neurite inhibition assay by CSPGs}

After CNS injury, chondroitin sulfate proteoglycans (CSPGs) are abundantly expressed in glial scar and exert inhibitory effect on axonal growth leading to poor regeneration [3-5]. Eliminating the restrictive effect of CSPGs and promoting neurite outgrowth in this inhibitory environment is an essential barrier to overcome for neural regeneration studies. In order to analyze the effect of CSPGs on the neurite-outgrowth-promoting activity of PA gels, we performed neurite outgrowth assay with PC-12 cells in the presence of CSPGs. The presence of CSPGs led to almost complete inhibition of neurite growth of PC-12 cells cultured on PDL surfaces (Fig. S7). Cells on collagen I coated surfaces experienced $92 \%$ reduction in neurite length and $95 \%$ reduction in the number of cells with neurites in the presence of CSPGs (Figs. 7 and 8). These results were in agreement with previous reports on the inhibitory effect of CSPGs on neurite growth $[46,47]$. Strikingly, cells that were cultured on PA scaffolds could overcome the inhibitory effect exerted by CSPGs (Figs. 7 and S7). When cells were cultured on PA scaffolds, neither neurite length nor number of cells with neurites changed significantly in the presence of CSPGs (Fig. 8). Although there were variations among the four PA gel systems, the differences among them were not statistically significant (One-way

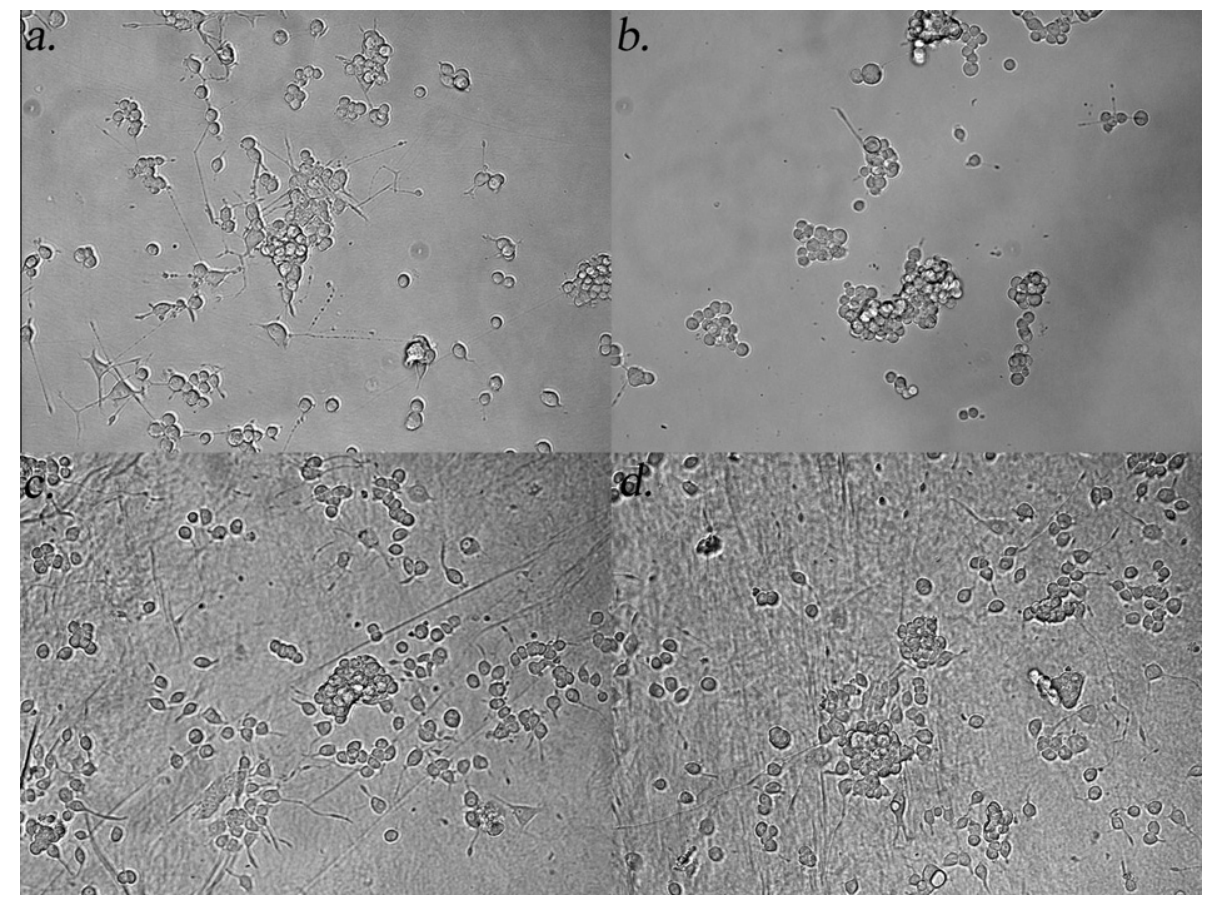

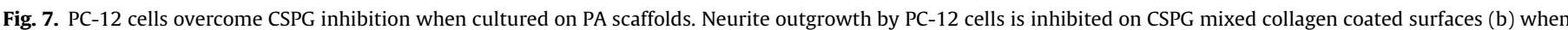

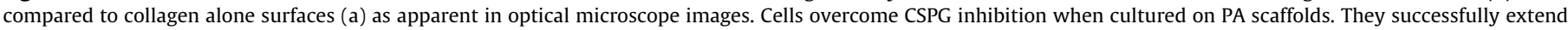
neurites on both CSPG added (d) and CSPG (c) IKVAV-PA/HSM-PA scaffolds. 

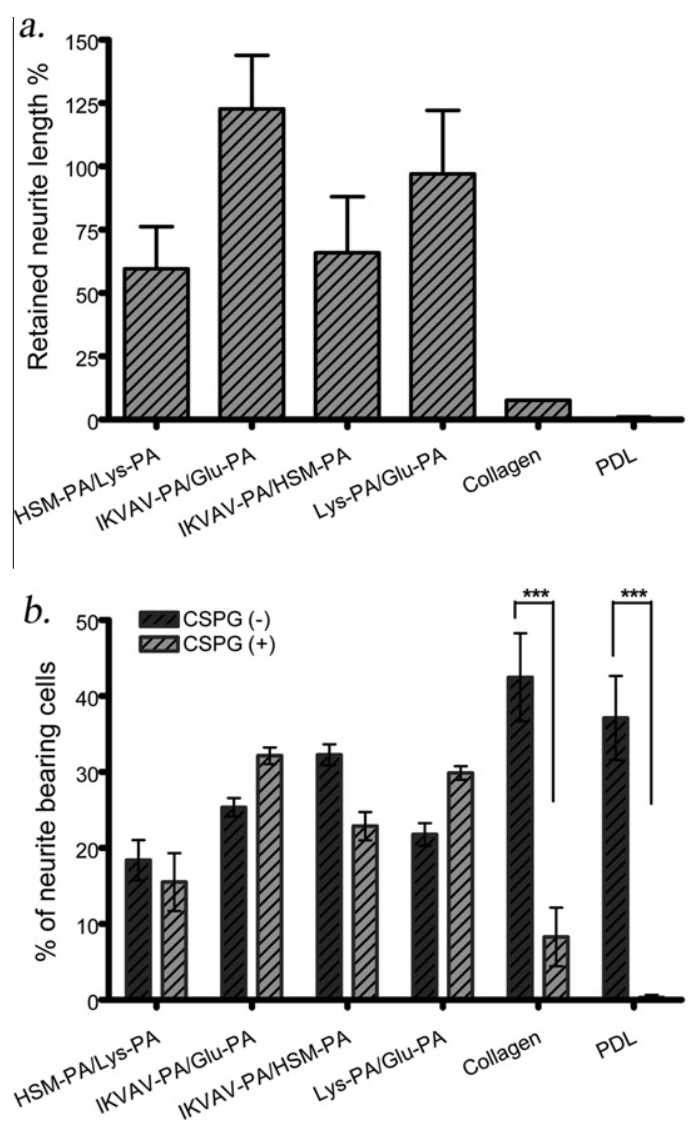

Fig. 8. PC-12 cells can extend neurites even in the presence of CSPGs when cultured on PA scaffolds. For all PA combinations, neurite lengths (a) and percentage of neurite extending cells (b) are not significantly different in CSPG added or not added surfaces while they decrease significantly on collagen and PDL coated surfaces when CSPG is used.

ANOVA, $p>0.05$ ). These data further indicate that the effect of laminin-derived PA scaffolds, which were previously shown to enhance recovery after spinal cord injury $[25,26]$, could in part be attributed to CSPG inhibition overcoming the effect of the PA nanofibers used in this study. The ability of PA nanofibers to help neural cells to overcome the inhibitory effect of CSPGs, further strengthens the potential of these PA nanofibers for neuroregenerative therapies, which currently face with the CSPG inhibition problem.

\section{Conclusions}

In this study, we developed a synthetic peptide nanofiber system mimicking neural ECM in terms of its neurite-outgrowth-promoting ability. These nanofibers contain laminin-derived peptide signals along with heparan-sulfate-mimicking groups interacting with growth factors active in neuronal regeneration. These two bioactive components of this scaffold were found to collectively act and promote neurite outgrowth of PC-12 cells effectively. In accordance with previous reports on full-length laminin-HSPG complexes, our completely synthetic composite scaffold induces much longer neurite formation when compared to the scaffold with laminin-derived signals alone. PA nanofiber scaffolds carrying laminin epitope alone were previously found to induce neural differentiation of stem cells as well as promoting axonal growth and serotonergic fiber plasticity besides inhibiting glial scar formation after spinal cord injury [24-26]. With the novel dual inducer peptide nanofiber scaffolds that are presented in this study, the effect of such nanofiber systems on neuroregeneration can be improved. Peptide scaffolds used in this study also aided cells to overcome the inhibitory effect of CSPGs on axonal growth. These results show that this newly developed peptide scaffold provides a promising novel therapeutic approach for neuroregeneration studies due to its neurite-outgrowth-promoting ability, even in the presence of inhibitory components that are abundant in the injured nervous system.

\section{Acknowledgements}

We would like to thank Z. Erdogan for help in LC-MS. We thank to S. Kocabey for synthesis and purification of HSM-PA and Lys-PA and E. Demir for her help in quantification of results. This project was supported by the Scientific and Technological Research Council of Turkey (TUBITAK) Grant Number 111M410 and COMSTECHTWAS Grant. R.M. is supported by TUBITAK BIDEB PhD fellowship. M.O.G. acknowledges support from the Turkish Academy of Sciences Distinguished Young Scientist Award (TUBA GEBIP).

\section{Appendix A. Figures with essential colour discrimination}

Certain figures in this article, particularly Figs. 1, 2, and 4, are difficult to interpret in black and white. The full colour images can be found in the on-line version, at doi: doi:10.1016/ j.actbio.2012.02.006.

\section{Appendix B. Supplementary data}

Supplementary data associated with this article can be found, in the online version, at doi:10.1016/j.actbio.2012.02.006. HPLC chromatograms, mass spectrometry analysis, biocompatibility results, immunofluorescent staining of synaptophysin in cells cultured on Lys-PA/Glu-PA substrate, optical images of PC-12 neurite extensions on different PA matrices and optical images of CSPG neurite inhibition assay for different PA matrices.

\section{References}

[1] NSCISC. Spinal cord injury facts and figures at a glance. Birmingham, Al: NSCISC; 2011.

[2] Statistics NCfH, Injury in the United States: 2007. Chartbook; 2007.

[3] Moon LD, Asher RA, Rhodes KE, Fawcett JW. Relationship between sprouting axons, proteoglycans and glial cells following unilateral nigrostriatal axotomy in the adult rat. Neuroscience 2002;109:101-17.

[4] Tang X, Davies JE, Davies SJ. Changes in distribution, cell associations, and protein expression levels of NG2, neurocan, phosphacan, brevican, versican V2, and tenascin-C during acute to chronic maturation of spinal cord scar tissue. J Neurosci Res 2003;71:427-44.

[5] Jones LL, Margolis RU, Tuszynski MH. The chondroitin sulfate proteoglycans neurocan, brevican, phosphacan, and versican are differentially regulated following spinal cord injury. Exp Neurol 2003;182:399-411.

[6] Chang WC, Hawkes E, Keller CG, Sretavan DW. Axon repair: surgical application at a subcellular scale. Wiley Interdiscip Rev Nanomed Nanobiotechnol 2010;2:151-61.

[7] Gardiner NJ. Integrins and the extracellular matrix: Key mediators of development and regeneration of the sensory nervous system. Dev Neurobiol 2011;71:1054-72.

[8] Baron-Van Evercooren A, Kleinman HK, Ohno S, Marangos P, Schwartz JP, Dubois-Dalcq ME. Nerve growth factor, laminin, and fibronectin promote neurite growth in human fetal sensory ganglia cultures. J Neurosci Res 1982;8:179-93.

[9] Manthorpe M, Engvall E, Ruoslahti E, Longo FM, Davis GE, Varon S. Laminin promotes neuritic regeneration from cultured peripheral and central neurons. J Cell Biol 1983;97:1882-90.

[10] Plantman S, Patarroyo M, Fried K, Domogatskaya A, Tryggvason K, Hammarberg $\mathrm{H}$, et al. Integrin-laminin interactions controlling neurite outgrowth from adult DRG neurons in vitro. Mol Cell Neurosci 2008;39:50-62.

[11] Koh HS, Yong T, Chan CK, Ramakrishna S. Enhancement of neurite outgrowth using nano-structured scaffolds coupled with laminin. Biomaterials 2008;29:3574-82.

[12] Armstrong SJ, Wiberg M, Terenghi G, Kingham PJ. Laminin activates NF-kappaB in Schwann cells to enhance neurite outgrowth. Neurosci Lett 2008;439:42-6. 
[13] Sakashita S, Engvall E, Ruoslahti E. Basement membrane glycoprotein laminin binds to heparin. FEBS Lett 1980;116:243-6.

[14] Ott U, Odermatt E, Engel J, Furthmayr H, Timpl R. Protease resistance and conformation of laminin. Eur J Biochem 1982;123:63-72.

[15] Edgar D, Timpl $R$, Thoenen $H$. The heparin-binding domain of laminin is responsible for its effects on neurite outgrowth and neuronal survival. EMBO J 1984;3:1463-8.

[16] Engvall E, Davis GE, Dickerson K, Ruoslahti E, Varon S, Manthorpe M. Mapping of domains in human laminin using monoclonal antibodies: localization of the neurite-promoting site. J Cell Biol 1986;103:2457-65.

[17] Hozumi K, Suzuki N, Uchiyama Y, Katagiri F, Kikkawa Y, Nomizu M. Chainspecific heparin-binding sequences in the laminin alpha chain LG45 modules. Biochemistry 2009;48:5375-81.

[18] Dow KE, Mirski SE, Roder JC, Riopelle RJ. Neuronal proteoglycans: biosynthesis and functional interaction with neurons in vitro. J Neurosci 1988;8:3278-89.

[19] Riopelle RJ, Dow KE. Functional interactions of neuronal heparan sulphate proteoglycans with laminin. Brain Res 1990;525:92-100.

[20] Hynes RO. The extracellular matrix: not just pretty fibrils. Science 2009;326:1216-9.

[21] Chu H, Johnson NR, Mason NS, Wang Y. A [polycation:heparin] complex releases growth factors with enhanced bioactivity. J Control Release 2011;150:157-63.

[22] Yurchenco PD, Cheng YS, Schittny JC. Heparin modulation of laminin polymerization. J Biol Chem 1990;265:3981-91.

[23] Yurchenco PD, Schittny JC. Molecular architecture of basement membranes. FASEB J 1990;4:1577-90.

[24] Silva GA, Czeisler C, Niece KL, Beniash E, Harrington DA, Kessler JA, et al. Selective differentiation of neural progenitor cells by high-epitope density nanofibers. Science 2004;303:1352-5.

[25] Tysseling VM, Sahni V, Pashuck ET, Birch D, Hebert A, Czeisler C, et al. Selfassembling peptide amphiphile promotes plasticity of serotonergic fibers following spinal cord injury. J Neurosci Res 2010;88:3161-70.

[26] Tysseling-Mattiace VM, Sahni V, Niece KL, Birch D, Czeisler C, Fehlings MG, et al. Self-assembling nanofibers inhibit glial scar formation and promote axon elongation after spinal cord injury. J Neurosci 2008;28:3814-23.

[27] Toksoz S, Mammadov R, Tekinay AB, Guler MO. Electrostatic effects on nanofiber formation of self-assembling peptide amphiphiles. J Colloid Interface Sci 2011;356:131-7.

[28] Smith CK, Withka JM, Regan L. A thermodynamic scale for the beta-sheet forming tendencies of the amino acids. Biochemistry 1994;33:5510-7.

[29] Mammadov R, Mammadov B, Toksoz S, Aydin B, Yagci R, Tekinay AB, et al. Heparin mimetic peptide nanofibers promote angiogenesis. Biomacromolecules 2011;12:3508-19.

[30] Nishida T, Yasumoto K, Otori T, Desaki J. The network structure of corneal fibroblasts in the rat as revealed by scanning electron microscopy. Invest Ophthalmol Vis Sci 1988;29:1887-90.
[31] Ruoslahti E. Brain extracellular matrix. Glycobiology 1996;6:489-92.

[32] Georges PC, Miller WJ, Meaney DF, Sawyer ES, Janmey PA. Matrices with compliance comparable to that of brain tissue select neuronal over glial growth in mixed cortical cultures. Biophys J 2006;90:3012-8.

[33] Teixeira AI, Ilkhanizadeh S, Wigenius JA, Duckworth JK, Inganas O, Hermanson 0 . The promotion of neuronal maturation on soft substrates. Biomaterials 2009;30:4567-72

[34] Engler AJ, Sen S, Sweeney HL, Discher DE. Matrix elasticity directs stem cell lineage specification. Cell 2006;126:677-89.

[35] Saha K, Keung AJ, Irwin EF, Li Y, Little L, Schaffer DV, et al. Substrate modulus directs neural stem cell behavior. Biophys J 2008;95:4426-38.

[36] Greene LA, Tischler AS. Establishment of a noradrenergic clonal line of rat adrenal pheochromocytoma cells which respond to nerve growth factor. Proc Natl Acad Sci USA 1976;73:2424-8.

[37] Vaudry D, Stork PJ, Lazarovici P, Eiden LE. Signaling pathways for PC12 cell differentiation: making the right connections. Science 2002;296:1648-9.

[38] Bovolenta P, Fernaud-Espinosa I. Nervous system proteoglycans as modulators of neurite outgrowth. Prog Neurobiol 2000;61:113-32.

[39] Dyer MA, Cepko CL. Regulating proliferation during retinal development. Nat Rev Neurosci 2001;2:333-42.

[40] Kwon SE, Chapman ER. Synaptophysin regulates the kinetics of synaptic vesicle endocytosis in central neurons. Neuron 2011;70:847-54.

[41] Liebau S, Vaida B, Storch A, Boeckers TM. Maturation of synaptic contacts in differentiating neural stem cells. Stem Cells 2007;25:1720-9.

[42] Harrill JA, Mundy WR. Quantitative assessment of neurite outgrowth in PC12 cells. Methods Mol Biol 2011;758:331-48.

[43] Korsching S, Thoenen $\mathrm{H}$. Nerve growth factor in sympathetic ganglia and corresponding target organs of the rat: correlation with density of sympathetic innervation. Proc Natl Acad Sci USA 1983;80:3513-6.

[44] Kemp SW, Webb AA, Dhaliwal S, Syed S, Walsh SK, Midha R. Dose and duration of nerve growth factor (NGF) administration determine the extent of behavioral recovery following peripheral nerve injury in the rat. Exp Neurol 2011;229:460-70.

[45] Wood MD, MacEwan MR, French AR, Moore AM, Hunter DA, Mackinnon SE, et al. Fibrin matrices with affinity-based delivery systems and neurotrophic factors promote functional nerve regeneration. Biotechnol Bioeng 2010;106:970-9.

[46] Gopalakrishnan SM, Teusch N, Imhof C, Bakker MH, Schurdak M, Burns DJ et al. Role of Rho kinase pathway in chondroitin sulfate proteoglycanmediated inhibition of neurite outgrowth in PC12 cells. J Neurosci Res 2008;86:2214-26.

[47] Hynds DL, Snow DM. Neurite outgrowth inhibition by chondroitin sulfate proteoglycan: stalling/stopping exceeds turning in human neuroblastoma growth cones. Exp Neurol 1999;160:244-55. 